\title{
Factors contributing to work related low back pain among personal care workers in old age
}

\author{
Simon S. Yeung \\ Department of Rehabilitation Sciences, The Hong Kong Polytechnic University, Hung Hom. Hong Kong
}

\begin{abstract}
This study aims to preliminary explore the work related and individual factors that contributed to the occurrence of low back pain (LBP) that affected work activities of Personal Care Workers (PCWs). A cross-sectional study was conducted to $36 \mathrm{PCWs}$ in an old age home of Hong Kong. The study is divided into three parts: 1) a questionnaire to document the workload exposure factors and the musculoskeletal symptoms survey of the PCWs, 2) work posture evaluation; and 3) an evaluation of the physical fitness and lifting capacity of the PCWs. Univariate analyses were used to explore the risk factors associated with LBP that affected work activities. The results indicated that individual physical profile and lifting capacities did not contribute to occurrence of low back pain at work. For the work demand factors, the perceived physical demands in lifting and lowering heavy objects, awkward sustain neck and back postures, loading on the back, and perceived effort of cleaning task contributed to the occurrence of LBP. For the physical environment factors, thermal stress and improper ventilation were associated with the occurrence of LBP cases. For the individual factor, LBP cases were associated with workers' self perceived muscular effort, and perceived risk of mental illness in response to work requirements.
\end{abstract}

Keywords: Low back pain, risk factors, personal care workers

\section{Introduction}

Low back pain (LBP) constituted the major work related muscuoskeletal disorders in the health care professionals. According to the Statistics on Occupational Injuries compiled by the Labour Department of the Government of the Hong Kong Special Administrative Region (HKSAR), the most common occupational injuries in Health Care is "injured whilst lifting or carrying", which accounted for $31.9 \%$ for all the occupational injury in 2009 [1]. In old age homes (OAH), personal care workers (PCWs) share the workload of nurses in most of the transfer and manual handling tasks and it has been reported that nursing aids are more likely to suffer from LBP than registered nurses [2-4]. LBP is multifactorial in origin and may be associated with both occupational and non work-related factors, and multifactorial interventions has been suggested to the best approach in alleviating the problems of LBP at the workplace [5]. Thus, the purpose of this study is to use a multifactorial approach to identify the possible risk factors that might contribute to the occurrence of LBP among PCWs in an old age home."

\section{Method}

\section{Study design}

The study is a cross sectional design applied to all the PCWs in a local Old Age Home. Workers with either disabling LBD symptoms (that required sick leave) during the last 7 days prior to the testing, or who have history of spinal surgery, diagnosed metabolic illness or cardiovascular disorders (such as rheumatoid arthritis, cardiovascular disease, diabetes, hypertension, malignancy, etc), or any severe pathology of prolapsed intervertebral disc were excluded from the study.

\section{Measurement of risk factors}

The interaction between the workload exposure and personal variables on the prevalence of LBD were evaluated. The study is divided into three parts: 1) a questionnaire to document the workload expo-

\footnotetext{
* Corresponding author e-mail: simon.yeung@polyu.edu.hk
} 
sure factors and the musculoskeletal symptoms survey of the PCWs, 2) work posture evaluation; and 3) an evaluation of the physical fitness and lifting capacity of the PCWs.

Work load exposure questionnaire and musculoskeletal symptoms survey

The questionnaire consists of three parts: work demand evaluation, self-perceived work ability, PCWs demographic data, and a musculoskeletalsymptoms survey. The work demand factors consist of 55 items aimed to document the physical task requirements, mental task requirements, physical environment requirements, and socio-organisation environmental requirements. The self-perceived work ability consists of 32 items to evaluate the workers' self perceived work ability in dealing with commonly performed physically demanding tasks, and tolerance to various work environment and characteristics. Each items was assessed using a 7 point rating scale with linguistic descriptor anchored with each of the scale, ie. "very very low", "very low", "low", "moderate", "high", "very high", and "very very high". This measure has been used in our previous studies in the evaluation of manual lifting tasks $[6,7]$. The questionnaire also included individual characteristics: age, education level, marital status and years of working experience.

\section{Posture evaluation}

The Ovako Working posture Analysis System (OWAS), which was originally used for the documentation of the work postures in the Finnish Steel industry [8] was used to estimate the frequency and repetitiveness of the various body postures when performing the work tasks. Four PCWs were conveniently selected by the head nurse for the video recording of their work tasks during an eight-hour daytime shift. Nine basic work tasks (preparing meal, feeding, putting on / removing clothes, wheelchair pushing, cleaning, transfer, showering, turning in bed, changing diaper) were chosen for analysis.

\section{Evaluation of physical fitness, lifting capacity and anthropometric measurement}

Among the thirty-six PCWs, thirty-two of them volunteered to perform a comprehensive physical fitness evaluation. These include cardiopulmonary fitness by Queens' College Step Test, Sit and reach test to document the joints flexibility, one minute sit up to represent muscle endurance, body composition, and three isometric lifting capacities (isometric arm lift, leg lift and back lift strength). The internal relia- bility of these tests has been reported to be high [912]. The body weight and height were measured for calculation of body mass index (BMI). All tests were performed with standard equipment and trained personnel. Rest period was given between each test.

\section{Case definition}

The LBP were assessed by a Chinese version of the Nordic Questionnaire, modified from the Nordic Musculoskeletal Symptom Survey [13] with body diagram to illustrate the respective body region as previously described [7].

\section{Data management and statistical analysis}

All analyses were performed using SPSS (Statistical Package for the Social Sciences) for window version 16.0 (Chicago, IL). Univariate logistic analyses were performed to identify variables that were significantly related to the occurrence of LBP.

\section{Results}

\section{Prevalence of low back pain.}

Table 1 shows the prevalence of LBP with various definitions. Ten $(27.8 \%)$ of them reported to have LBP that limited their work activities in the past 12 months. For the purpose of this study, LBP was defined as the presence of any "aches, pains, or discomforts" in the lumbar or low back region in the past 12 months that limited their work activities at work but do not required any sick leave.

\section{Physical fitness profile}

Table 2 shows the physical fitness profile and the anthropmetric measurement of the PCWs. Independent T-test reveals no significant different between the LBP cases and non-LBP cases.

\section{Postural analysis}

A total of 2,162 observations of the nine basic tasks were recorded. Table 3 shows the percentage of time spent in the recording of the nine basic activities. Among them, changing diaper (79.4\%), transfer $(66.7 \%)$ and putting on / removing clothes $(65.0 \%)$ are the top three tasks with poor back posture.

\section{Self perceived work demands factors}

Table 4 shows the descriptive rating of the workers' perceived work demands and self perceived work capacity. 
Table 1

Prevalence of low back pain (LBP)

\begin{tabular}{lll}
\hline LBP & $\mathrm{n}$ & percen- \\
\hline $\begin{array}{l}\text { 1. Have you ever had trouble in lower } \\
\text { back }\end{array}$ & 34 & $94.4 \%$ \\
2. 12-month prevalence and duration: & & \\
- 1-7 days & 6 & $16.6 \%$ \\
- 8-30 days & 7 & $19.4 \%$ \\
- >30 days & 8 & $22.2 \%$ \\
- Everyday & 13 & $36.1 \%$ \\
- N/A & 2 & $5.5 \%$ \\
3. LBP reduced leisure in past 12-month & 18 & $50.0 \%$ \\
4. LBP prevalence during the last 7 days & 18 & $50.0 \%$ \\
5. LBP limited their work in past 12- & 10 & $27.8 \%$ \\
month* & & \\
\hline
\end{tabular}


Table 2

Physical fitness profile and the anthropmetric measurement of the PCWs (LBP vs non=LBP group

\begin{tabular}{|c|c|c|c|c|c|}
\hline Variable & LBP & Mean & SD & $\mathrm{t}$ & $\mathrm{p}$ \\
\hline Age & $\begin{array}{l}\text { no } \\
\text { yes }\end{array}$ & $\begin{array}{l}41.58 \\
42.70\end{array}$ & $\begin{array}{l}4.60 \\
5.95\end{array}$ & 0.60 & 0.55 \\
\hline Height $(\mathrm{cm})$ & $\begin{array}{l}\text { no } \\
\text { yes }\end{array}$ & $\begin{array}{l}153.83 \\
156.28\end{array}$ & $\begin{array}{l}4.35 \\
3.73\end{array}$ & 1.57 & 0.26 \\
\hline Body weight (lb) & $\begin{array}{l}\text { no } \\
\text { yes }\end{array}$ & $\begin{array}{l}56.51 \\
60.40\end{array}$ & $\begin{array}{l}6.84 \\
11.55\end{array}$ & 1.25 & 0.22 \\
\hline Resting HR (beat/min) & $\begin{array}{l}\text { no } \\
\text { yes }\end{array}$ & $\begin{array}{l}79.14 \\
76.75\end{array}$ & $\begin{array}{l}10.18 \\
11.81\end{array}$ & 0.60 & 0.55 \\
\hline Recovery HR at post 1 min step test & $\begin{array}{l}\text { no } \\
\text { yes }\end{array}$ & $\begin{array}{l}123.80 \\
120.88\end{array}$ & $\begin{array}{l}19.46 \\
15.79\end{array}$ & 0.48 & 0.63 \\
\hline Sit and reach flexibility $(\mathrm{cm})$ & $\begin{array}{l}\text { no } \\
\text { yes }\end{array}$ & $\begin{array}{l}27.52 \\
30.54\end{array}$ & $\begin{array}{l}7.34 \\
7.34\end{array}$ & 1.10 & 0.28 \\
\hline Sit up (repetition/min) & $\begin{array}{l}\text { no } \\
\text { yes }\end{array}$ & $\begin{array}{l}12.11 \\
12.60\end{array}$ & $\begin{array}{l}8.67 \\
5.64\end{array}$ & 0.17 & 0.87 \\
\hline Body fat composition (percentage) & $\begin{array}{l}\text { no } \\
\text { yes }\end{array}$ & $\begin{array}{l}25.31 \\
26.80\end{array}$ & $\begin{array}{l}4.20 \\
6.55 \\
\end{array}$ & 0.81 & 0.42 \\
\hline Left hand grip strength $(\mathrm{kg})$ & $\begin{array}{l}\text { no } \\
\text { yes }\end{array}$ & $\begin{array}{l}27.90 \\
25.87\end{array}$ & $\begin{array}{l}4.69 \\
2.96 \\
\end{array}$ & 1.27 & 0.21 \\
\hline Right hand grip strength $(\mathrm{kg})$ & $\begin{array}{l}\text { no } \\
\text { yes }\end{array}$ & $\begin{array}{l}28.41 \\
27.92 \\
\end{array}$ & $\begin{array}{l}4.46 \\
2.76 \\
\end{array}$ & 0.32 & 0.75 \\
\hline Left hand pinch grip strength $(\mathrm{kg})$ & $\begin{array}{l}\text { no } \\
\text { yes }\end{array}$ & $\begin{array}{l}7.86 \\
7.35\end{array}$ & $\begin{array}{l}0.92 \\
0.68\end{array}$ & 1.59 & 0.12 \\
\hline Right hand pinch grip strength (kg) & $\begin{array}{l}\text { no } \\
\text { yes }\end{array}$ & $\begin{array}{l}8.11 \\
8.07\end{array}$ & $\begin{array}{l}0.99 \\
0.63\end{array}$ & 0.12 & 0.91 \\
\hline Isometric arm lift strength $(\mathrm{kg})$ & $\begin{array}{l}\text { no } \\
\text { yes }\end{array}$ & $\begin{array}{l}21.67 \\
19.92 \\
\end{array}$ & $\begin{array}{l}6.47 \\
4.09 \\
\end{array}$ & 0.79 & 0.43 \\
\hline Isometric leg lift strength $(\mathrm{kg})$ & $\begin{array}{l}\text { no } \\
\text { yes }\end{array}$ & $\begin{array}{l}55.35 \\
62.00\end{array}$ & $\begin{array}{l}20.00 \\
15.94\end{array}$ & 0.94 & 0.35 \\
\hline Isometric back lift strength $(\mathrm{kg})$ & $\begin{array}{l}\text { no } \\
\text { yes }\end{array}$ & $\begin{array}{l}57.33 \\
55.33\end{array}$ & $\begin{array}{l}16.33 \\
12.82\end{array}$ & 0.35 & 0.74 \\
\hline
\end{tabular}

P-value $>0.05$ in independent t-test 
Table 3

Percentage of time spent in the observation of the nine basic activities

\begin{tabular}{lc}
\hline Task & \% of observed time \\
\hline Preparing meal & 19.4 \\
Feeding & 16.5 \\
Putting on/ Remove clothes & 6.4 \\
Wheelchair pushing & 6.2 \\
Cleaning & 5.7 \\
Transfer & 5.6 \\
Showering & 4.5 \\
Turning in bed & 3.9 \\
Changing diaper & 3.2 \\
Other activities & 28.5 \\
\hline
\end{tabular}


Table 4

Self-perceived work demands and work capabilities

\section{PART I}

\section{A. Self-perceived working ability}

1. Heavy objects in upright position

2. moderately heavy objects continuously in upright position

3. maintaining the lower extremity in continuous standing and sitting

4. maintaining the lower extremity in continuous walking

5. repetitive and continuous upper extremity activities

6. repetitive and continuous head and neck activities

7. repetitive and continuous low back activities

8. repetitive and continuous lower extremity activities

9. continuous, awkward upper extremity fixed positions

10. continuous, awkward head fixed positions

11. continuous, awkward low back fixed positions

12. large fixed forces using the upper extremity

13. large fixed forces using the lower extremity

14. continuous, moderate fixed forces using the upper extremity

15. moderate fixed forces using the lower extremity

16. self-perceived ability to handle mental demand per day

\section{B. Self-perceived working tolerance}

17. extreme physical factors e.g. noise, vibration, improper lighting

18. physical hazards e.g. kinetic, mechanical, fall

19. extreme non-toxic chemical factors e.g. dust, fumes

20. toxic chemical hazards e.g. solvents, carcinogens

21. non-supportive social environment

22. non-supportive organizational environment

23. non-supportive technical environment

24. muscular effort

26. perceived risk of physical illness or injury

27. perceived risk of mental illness

\section{Self-perceived ability status}

28. muscular fatigue
29. mental fatigue
30. boredom
31. freshness to perform muscular work
32. freshness to perform mental work

32. freshness to perform mental work 


\section{PART II}

\section{A. Work factors analysis: physical demand}

1. lifting and lowering heavy objects

0.96

2. carrying heavy objects

4.61

1.10

3. pushing and pulling heavy objects

$5.11 \quad 1.07$

4. lifting and lowering moderately heavy objects continuously

5. carrying moderately heavy objects

6. pushing and pulling moderately objects continuously

8. sitting

9. squatting and crouching

10. walking

11. climbing stairs, ladders, and ramps

12. crawling

13. repetitive activities: upper limbs

14. repetitive activities: neck

15. repetitive activities: back

16. repetitive activities: lower limbs

17. awkward fixed position: upper limbs

18. awkward fixed position: neck

19. awkward fixed position: back

20. awkward fixed position: lower limbs

21. fixed force or load on: upper limbs

22. fixed force or load on: neck

23. fixed force or load on: back

24. fixed force or load on: lower limbs

25. physical task demand: in and out bed

26. physical task demand: turning the patient

27. physical task demand: walk the patient

28. physical task demand: showering

29. physical task demand: bedding

30. physical task demand: cleaning

31. physical task demand: feeding patient 


\section{B. Work factors analysis: mental demand}

\section{Work environment evaluation: environmental factor}

33. physical environment condition: noise $\quad 5.18$

34. physical environment condition: vibration

35. physical environment condition: thermal stress

36. physical environment condition: improper lighting

37. physical environment condition: improper ventilation

38. physical environment condition: mechanical hazards

39. physical environment condition: fall hazards

40. physical environment condition: immediate danger to life and death

41. physical environment condition: non-toxic chemical factors

42. physical environment condition: toxic chemical hazards

\section{Work environmental evaluation: non-environmental factor}

43. non-physical environment condition: social support provided by supervisor 3.95

44. non-physical environment condition: social support provided by peers

45. non-physical environment condition: praise

46. non-physical environment condition: nurturing

47. non-physical environment condition: participation in decision-making

48. non-physical environment condition: relevant, accurate and timely feedback information

49. non-physical environment condition: adequacy of work benefits

50. non-physical environment condition: income and employment security

51. non-physical environment condition: time available to do the work

52. non-physical environment condition: staff support

53. non-physical environment condition: availability and functionality of tools/ equipment/ supplies

54. non-physical environment condition: technical information and training

55. non-physical environment condition: technical supervision

* highest mean value among the sub-groups of self-perceived capacity and work demand 


\section{Univariate logistic regression}

Table 5 shows the summary of the univariate logistic regression analyses. The results indicated that individual physical profile and lifting capacities did not contribute to occurrence of low back pain at work. For the work demand factors, the perceived physical demands in lifting and lowering heavy objects, demands of awkward sustain neck and back postures, demands of loading on the back, and perceived effort of cleaning task contributed to the occurrence of LBP. For the physical environment factors, thermal stress and improper ventilation were associated with the occurrence of LBP cases. For the individual factor, LBP cases were associated with workers' self perceived muscular effort, and perceived risk of mental illness in response to work requirements.

\section{Discussion}

\section{Prevalence of $L B P$}

The muscuoskeletal symptoms survey revealed a very high prevalence of LBP in this group of PCWs. Among all the PCWs, only two of them did not have any symptoms of LBP in the past 12 months. This figure is similar to the one that we conducted to a group of female nurses working in hospital setting [14].

\section{Physical fitness and lifting capacity}

Result of this study did not indicate any association between physical fitness and LBP. This corroborated with our earlier study in non-emergency ambulance workers that personal fitness is not a core factor contributed to work-related LBP [15].

\section{Work posture}

It was noticed that $50 \%$ of the 2,162 observed posture were identified as harmful back postures according to OWAS. Meal feeding to clients and preparation of meal constituted the two most frequently performed harmful task (14 and 9\% respectively). For these two tasks, the PCWs normally adopted a bend, twisted or prolonged stooping postures. Our recent study on the association between back pain and trunk posture of workers in a special school for the severe handicaps also revealed subjects with LBP spent significantly longer percentage of time in static trunk posture when compared to normal [16]. Thus, analysis of workers' posture throughout the entire working shift is essential when assessing the risk factors associated with the LBP.

\section{Self-perceived work demand and work capacity}

The results of this investigation indicated that workers' perceived physical demands in lifting and lowering heavy objects, demands of awkward sustain neck and back postures, demands of loading on the back, and perceived effort of cleaning task contributed to the occurrence of LBP. For the physical environment factors, thermal stress and improper ventilation were associated with the occurrence of LBP cases. These all are related to the work environment. Indeed, environmental work constraints will stress the PCWs lower back when they have to assist the client to get up from bed as they have to sustain the back in flexed position when performing this task. The study also indicated that workers' perceived exertion at work is a strong indication of musculoskeletal complaints. Our previous study also showed an increase in risk $(\mathrm{OR}=7.95)$ of developing LBP among non-emergency ambulance transfer workers when workers' perceived high effort exertion at work [15]. Nonetheless, it has to take note that in the present investigation, both the exposure (perceived work load) and outcome variables (LBP) were assessed by self-reports, workers with negative affectivity may have perceived their work load more negatively. Thus, there was potential of bias from the workers' evaluation and reporting of symptoms.

\section{Conclusion}

The findings of the risk factors for LBP among PCWs should be interpreted with caution as causality cannot be established from this cross-sectional study. Also, the inclusion of PCWs only in one nursing home must be considered when interpreting the data. Nonetheless, the results of the current study corroborated with many studies that indicated work environment contributed to the LBP at work. While ergonomics design and workers' training might serve a role in the prevention of LBP at work, workers' perceived exertion at his workplace might has an invaluable role in assessing the risk that contributed to the work-related LBP. To avoid progression of LBP at the workplace, work adjustment or modification should be considered when workers reported high level of perceived exertion at work. 
Table 5

Univariate analyses of the associations of LBP cases with the risk factors

\begin{tabular}{|l|c|c|c|}
\hline & & $95 \%$ CI & Upper \\
\hline Variables & OR & Lower & 12.73 \\
\hline Physical task demands in lifting and lowering heavy objects * & 3.24 & 0.824 & \\
\hline Perceived demands of awkward sustain neck postures* & & & 1.09 \\
\hline Perceived demands of awkward sustain back postures* & 0.66 & 0.40 & 7.85 \\
\hline Perceived demands of loading to back* & 2.31 & 0.68 & 5.71 \\
\hline Perceived effort in cleaning task** & 2.98 & 0.78 & 10.06 \\
\hline Perceived thermal stress at work** & 2.57 & 1.15 & 4.20 \\
\hline Perceived improper ventilation at work* & 3.22 & 1.03 & 47.49 \\
\hline Perceived muscular effort exerted in response to work require- & 6.31 & 0.79 & 5.54 \\
\hline ments* & & & \\
\hline
\end{tabular}

$* \mathrm{p}<0.1$

$* * \mathrm{p}<0.05$

Variables not associated with LBP cases: age $(p=0.54)$, muscle strength $(p=0.11)$, cardiovascular fitness $(p=0.50)$, flexibility $(p=0.34)$, years of work experience in manual handling $(p=0.21)$ 


\section{References}

[1] Department of Labour. (2010). Statistics on Occupational Injuries Compiled by the Labour Department of Government Hong Kong Special Administration Region. 2010: http://www.labour.gov.hk/eng/osh/content10.htm

[2] Guo, HR. (2002). Working hours spent on repeated activities and prevalence of back pain. Occup Environ Med 59, 680-688

[3] Eriksen, W. (2003). The prevalence of musculoskeletal pain in Norwegian nurses' aides. International Archives Occupational Environmental Health 76, 625-30.

[4] Trinkoff, A.M., Johantgen, M., Muntaner, C., \& Le R. (2005). Staffing and worker injury in nursing homes. Am J Public Health, 95, 1220-1225.

[5] Dawson, A.P., McLennan, S.N., Schiller, S.D., Jull, G.A., Hodges, P.W., \& Stewart. S. (2007). Interventions to prevent back pain and back injury in nurses: a systematic review. Occup Environ Med, 64, 642-650.

[6] Yeung, S., Genaidy, A., Deddens, J., Alhemood, A., \& Leung, P.C. (2002). Prevalence of musculoskeletal symptoms in single and multiple body regions and effects of perceived risk of injury among manual handling workers. Spine 27(19), 2166-2172.

[7] Yeung, S.S., Genaidy, A.M., Karwowski, W., \& Leung, P.C. (2002). Reliability and validity of self-reported assessment of exposure and outcome variables for manual lifting tasks: a Preliminary investigation. Applied Ergonomics 33, 463-469.

[8] Karhu, O., Kansi, P,. \& Kurinka, I. (1977). Correcting working posture in industry: a practical method for analysis. Applied Ergonomics 8, 199-201.
[9] Jackson, A.S., Pollock, M.L., Graves, J.E., \& Mahar, M.T. (1988). Reliability and validity of bioelectrical impedance in determining body composition. Journal of Applied Physiology 64, 529-534.

[10] Morrow, J.R, \& Jackson, A.W. (1995). Disch JG, Mood D. Measurement and evaluation in human performance, $1^{\text {st }}$ ed., Champaign, IL: Human Kinetics Publishers Inc.

[11] Safrit, M.J., \& Wood, T.M. (1995). Introduction to measurement in physical education and exercise science, $3^{\text {rd }}$ ed. St. Louis, MO: Mosby-Year Book Inc.

[12] Heyward, VH. (1998). Advanced fitness assessment and exercise prescription, $3^{\text {rd }}$ ed., Champaign, IL: Human Kinetics Publishers Inc.

[13] Kuorinka, I., Jonsson, B., Kilborm, A., Vinterberg, H., Biering-Soremsen, F., Andersson, G., \& Jorgensen, K. (1987). Standardized Nordic questionnaires for the analysis of musculoskeletal symptoms. Applied Ergonomics 18 (3), 233-237.

[14] Yeung, S.S., Genaidy, A., \& Levin, L. (2004). Prevalence of musculoskeletal symptoms among Hong Kong nurses in single and multiple body regions. Occupational Ergonomics 4(3), 199-208.

[15] Tam, G.Y.T., Yeung, S.S. (2006), Perceived effort and low back pain in non-emergency ambulance workers: Implications for rehabilitation. Journal of Occupational Rehabilitation 16, 231-240.

[16] Wong, K.C., Lee, R.Y., \& Yeung, S.S. (2009) The association between back pain and trunk posture of workers in a special school for severe handicaps. BMC Musculoskeletal Disorders, 10. 43 doi:10.1186/1471-2474-10-43 